\title{
Thought on German Classical Aesthetics and German Industrial Design Idea under Aesthetics View
}

\author{
$\mathrm{XuFu}$ \\ Zibo Normal College, Zibo, 255130, China
}

Keywords: Aesthetics view, Germany classical aesthetics, German industrial design, Design idea, Thought

\begin{abstract}
Germany classical aesthetics was created by Kant. Driven by Hegel, idealistic aesthetics formed. Prior to Marxism, certain-scale aesthetic ideology which developed to systematization had formed. Hegel's aesthetics is also the ideological source of Marxist aesthetics. Ideology formed on this basis has become a thinking pattern which combines sensibility and reason. Art introspection in Germany classical aesthetics is combined with beauty pursuit. Art is defined as beauty category and it is also external presentation of internal free thought. Based on the lofty position gained by Germany classical aesthetics, artistic characteristics are introduced in German industrial design, which not just makes industrial design works more orderly and rigorous, but also becomes a part of German national spirit. This paper studies Germany classical aesthetics and German industrial design idea under aesthetics view.
\end{abstract}

\section{Introduction}

Kant is the founder of Germany classical aesthetics, while Hegel pushed Germany classical aesthetics to the peak and defined aesthetics as "philosophy of art". Hegel established beautify on the basis of idea. He not merely affirmed art price of beauty, but also set forth social meaning of beauty. When philosophy of art presents by ideology, it is sensible image of art. In the opinion of Hegel, natural beauty is the basic stage in ideal development process and also the low-level form of beauty. When natural beauty is proceed by human, artistic beauty of soul forms. Such beauty generated from soul fully shows human pursuit of dreams and reflects human desire for freedom. In German industrial design idea, Hegel's philosophy of art still occupies a core position. In particular, industrial technology has become a part of people's life now. It not only reflects social development, but also accelerates social changes. The research on Germany classical aesthetics from aesthetic perspective with fusion of German industrial idea has important significance for the study on industrial design.

\section{Germany classical aesthetic ideology}

\section{Art itself is a kind of culture}

Art presents human reason and contains subjective purpose. Art creators need to own the ability of image aesthetics. This means art works with great aesthetic value is the result of appreciation and talents. As per Germany classical aesthetic ideology, any art is not gained due to the stimulus of sense organs in essence, but the result of rational judgment based on appreciation. According to Kant's comprehension, art itself is a kind of culture and can push human spirit to the height of spirit.

\section{Art is processing and creation of nature}

From aesthetic perspective, art is a kind of processing at the subjective level, i.e. presentational world is externalized to the ting which can be felt visually. Thus, art owns universality. However, it is not just simply listing of natural details, but the essence is extracted from universality of things. Art is not nature of course, but it does not break away from nature completely and is the processing and creation of nature. 


\section{Art is a kind of spiritual state}

Human pursuit of art is not absolute, but a kind of creative freedom reason. Art is expressed through practical activities after the idea forms in the heart. But, it is not mechanical imitation of real life, but promotes such idea to the spiritual state and becomes a kind of ideal. When art elements are introduced in real life, the thought from the inner heart will be externalized to fascinating situation while the heart aim appears. This means art should fuse idea in real life and achieve unity of contents and forms. On this basis, Hegel divided art into five systems: architecture, sculpture, painting, music and poem. From the matters overwhelming spirit to spirit surpassing matters, Germany classical aesthetics system established by Hegel has generated great influence on Germany art thought ${ }^{[1]}$.

\section{German industrial design idea}

In the earth $20^{\text {th }}$ century, German rationalism ideology was strong, which has generated huge effects in industrial design idea. At this time, a representative ideologist in Germany Bauhaus considered although industrial technology did not need art, the two had no difference. Hence, the new unity of art and technology formed.

For industrial product design, both product functions and design idea should stick to objective attitude and design based on science and technology. Although design ideological trend rose, German was not influenced. It was still based on rationalism design.

Germany experienced two world wars, so national economy was on the edge of collapse. German had no sufficient capital in industrial production, so the design products were mostly simple geometric shapes without too many decorations. Due to German traditional reason and orderliness as well as thinking spirit, industrial design became a part of German national spirit. German industrial design mostly reflects mathematics results. During design as per certain mathematics ratio and exploration of standard mechanical production, the beauty of technology should be studied. Natural technological design was reflected through art image.

From the second half of $20^{\text {th }}$ century, German industrial design developed rapidly. In terms of design idea, German industrial design was on longer constrained by traditional thought. However, driven by industrial wave, emerging art design movement rose. Large batches of design schemes mechanically produced started to enter the exploration stage. In 1930s, Germany was ruled by Nazis. In this period, industrial design stressed standardization of volume production to improve people's life quality. Thus, class consciousness of German people was weakened and "social equality" was achieved through standardization of industrial design. Meanwhile, social stability was promoted.

In 1960s-1970s, German industrial products were accepted by consumers by virtue of rational design, high quality and stable performance. In 1980s, German cried out "the best design is the least design" and proposed higher requirements for quality. Art form of industrial products should be valued. Besides, fluent appearance design was required to attract more consumers to improve industrial competitiveness, except excellent functions.

\section{Reflection of German classical aesthetics in industrial design}

\section{Rational design style of German classical aesthetics}

As per German classical aesthetics, German aesthetics belongs to the category of art philosophy. Industrial products designed according to such aesthetic idea should own external appearance beauty, but also reflect German spirit, i.e. reason, order and stability. German industrial design idea requires industrial products to pay attention to quality and penetrate the commutation through shape design. Meanwhile, logic and order should be highlighted. Thus, continuity of industrial product design was achieved under the uniform precondition, and original chaotic shape became orderly ${ }^{[2]}$.

For example, the design of German Volkswagen Beetle gives full play to German classical aesthetics in design. Volkswagen Beetle was designed in 1930s. The designer is German famous designer Ferdinand Porsche. Car body size of Volkswagen Beetle is very small, and functional design focuses on practicability. In addition, it is suitable for volume production. Till now, Volkswagen 
Beetle is still welcomed and is one of small cars favored by people. Seeing from its shape, it adopts bright color to form orderly geometrical morphology on the car body. Pure and concise design generates logic effect, which complied with industrial design style of German classical aesthetic ideology. Moreover, favorable appearance design of Volkswagen Beetle and function design style own features of German classical aesthetics. Although German industrial products penetrate too rational design thought, emphasize mechanization and lack human interest, they are not expelled out of the market, and exist in the capacity of "the old".

\section{Reflection of German classical aesthetics in product design}

With regard to refection of German industrial design thought, the products designed by Braun Company own certain representativeness. Since the setup of Braun Company, electrical devices it produces have not owned price advantage, but the sale volume is very high. One of the important reasons lies in its product design style. In 1950s, chief designer of electrical appliance design in Braun Company was Dieter Rams which is a representative of German classical aesthetic ideology. In the process of electrical device design, design philosophy is rigorous and concise and decorations are used rarely. These thoughts are fully reflected in product design. For instance, for radio design with the function of CD machine, the radio is of square, so the metal shell is fully closed, and organic glass cover is used, aiming at radio design, functions are also prompted.

\section{Influence of German classical aesthetics on German industrial design idea}

The influence of German classical aesthetics on German industrial design idea is very profound. The charm of German classical aesthetics has been no longer limited to the surface, but improved to era spirit and integrated classic and harmony. It pushes aesthetics to the peak of cultural art. German classical aesthetics is not only restricted to cultural art, but penetrates wisdom. The synthesis of aesthetics and philosophy is reflected through aesthetic ideology.

German classical aesthetics achieves fusion of aesthetics and philosophy. Kant is the founder and expressed rich aesthetic ideology through philosophy from the perspective of antinomy. Hegel considered Kant created a new state of aesthetics and critically summarized German classical aesthetics. As per the development sequence of German classical aesthetics, it entered another peak stage after western aesthetics experienced the enlightenment stage. German classical aesthetics has significant influence on aesthetic ideology and aesthetic positioning and becomes a direct source of aesthetic ideological trend ${ }^{[3]}$. German classical aesthetics has gradually formed contemporary practice -based aesthetics and has important significance for German industrial design idea.

Under the influence of German classical aesthetics, German industrial design thought fuses aesthetic spirit on the basis of traditional rational design. Industrial products should not just own functionality and practicability, but also highlight aesthetic value. German famous industrial designer Dieter Rams put forward design philosophy based on German classical aesthetics and considered complex decoration should be eliminated in industrial design and design should be as concise as possible to give people clean visual effect. In his opinion, such design is the best design. From the perspective of industrial products, aesthetics demand of products should be simple and prudent in the design process, and there should be equilibrium sense. Besides, the obstacles should be eliminated. When redundant things are removed, important things will be enhanced. Moreover, in industrial design process, users' aesthetic orientation is valued, but design thought should not excessively focus on decoration and fashion. For instance, for household appliance design, the design of German products is often concise and the operation is very convenient. Compared with some household appliances with fashionable shape, German products are more practical and do not lose beauty. German classical aesthetic ideology is penetrated in such design. German classical aesthetic ideology requires the products should be rigorous, orderly and practical. In the view of German industrial designers, if industrial products have no material application value, there will be no sense of beauty. So, the application of rationalism in industrial design exactly reflects humanization ${ }^{[4]}$.

German industrial design owns both rationalization and comprehensiveness. In other words, industrial products designed should satisfy users' demand to the largest extent and stress logic 
sequence while giving play to functions. For instance, concise geometric modeling will not bring random and hot visual effect, but reason penetrated from these geometrical elements as the soul of the products is more restrained. Thus, German rational spirit is revealed. In German industrial products, industrial production trace is penetrated in design aesthetics. German industrial products realize the combination of art and technology and fuse affective thinking and rational thinking so that German industrial design is improved under the function of rational force.

\section{Conclusion}

In conclusion, the formation of German industrial design idea is closely related to German classical aesthetics. Designers should not merely stress external package of products, but also undertake technical responsibilities in product design process, i.e. reason is fused in design behavior. With the development of world industrial economy, German industrial products are accepted by consumers. This is not just because of the development of science and technology, but also because design behavior is influenced by German classical aesthetics. Based on rational design, Germanism is fused in design idea. The life style and life quality are improved through design, and social harmony and stability are also achieved.

\section{References}

[1] Zeng Fanren, Rethinking on German classical aesthetics and Chinese contemporary aesthetics construction - from practical aesthetics of "human and nature" to ecological aesthetics of "heaven and earth state” . Theoretical Studies In Literature and Art, 2012 (01): 4-9.

[2] Judith M. Emscher Park, Germany-expanding the definition of a "park”. In: David Harmon, eds. Crossing Boundaries in Management : Proceeding of the 11th Conference on Research and Resource Management in parks and on Public Lands. Hancock, Michigan: The George Wright Society, 2001, 222-227.

[3] Zong Mingming, Wang Rouyi, Historical fragment - formation track of German industrial design idea . Theoretical Research, 2013 (13): 50-59.

[4] Chen Jian, Fan Shengxi, Chinese and foreign art design history. Beijing: China Building Materials Press, 2008, 216-238. 